БУТЬКО Т. В., д.т.н., професор, КОСТЮК О. А., магістрант

(Український державний університет залізничного транспорту)

\title{
Підходи до формування ризик-оріснтованої технології роботи станції Харків-Сортувальний в умовах обробки вагонів 3 небезпечними вантажами
}

У задачах планування оперативної роботи сортувальної станції (CС), в умовах проведення технологічних операцій, щзо містять вагони з небезпечними вантажами (НВ), потрібно вирімувати питання з удосконалення роботи СС, які забезпечать як скорочення експлуатаційних витрат, так $i$ зменшення можливих ризиків. Результатом вирішення таких управлінських задач може стати формалізація роботи СС з метою подальшої автоматизачї̈ процесу прийняття рішень на основі інтелектуального управління. Для вирішення такого типу завдань було проаналізовано технологію роботи станиії Харків-Сортувальний (Х-С), проведено статистичні дослідження щзодо кількості вагонів з НВ та часу їх перебування на станиії $і$ сформовано підходи до розроблення моделі оцінювання ризику оперативного планування.

Ключові слова: вагони з небезпечними вантажами, сортувальна станція, оперативне управління, автоматизація, оптимізація, технологія інтелектуального управління.

\begin{abstract}
Актуальність
Нарощування обсягів перевезень вагонів 3 НВ $\epsilon$ світовою тенденцією останніх років, в якій Україна $є$ доволі успішним індикатором цього тренду. Це підтверджується державною статистикою минулих років, що підкріплюється наявністю зростаючого тренду обсягів перевезень НВ.

У таких умовах особливу увагу потрібно приділяти технології роботи СС, яку доцільно розглядати як ХАБ, що містить значну кількість вагонів 3 НВ, де ситуація змінюється як у просторі, так і у часі. Таким чином, робота, присвячена удосконаленню технології роботи СС в умовах обробки вагонів $3 \mathrm{HB}$, є актуальною.
\end{abstract}

\section{Постановка проблеми}

Для вдосконалення технології роботи СС в умовах обробки вагонів з НВ доцільно провести статистичні дослідження щодо кількості вагонів 3 HВ різних класів та їх зміни на СС як у просторі, так і у часі для подальшої автоматизації роботи та процесу прийняття управлінських рішень.
}

\section{Викладення основного матеріалу}

Як довів аналіз (рис. 1), спостерігається стійка тенденція до значного зростання кількості перевезених вагонів з НВ у системі АТ УЗ.

Так, у 2019 році було перевезено 352279 тис. вагонів з НВ, що порівняно з 2018 роком більше на 56834 вагони. Таким чином, обсяг перевезень вагонів з НВ збільшився на $16 \%$.

Для докладного аналізу було сформовано динаміку розподілу кількості вагонів з НВ за місяцями у системі АТ УЗ (рис. 2).

Аналіз цієї динаміки довів наявність чіткої помісячної нерівномірності обсягів перевезених вагонів 3 НВ. Середня кількість перевезених вагонів складає $\mathrm{N}$ ваг $=29356$ ваг\міс, при цьому середнє квадратичне відхилення складає б ваг = 17208 ваг〉міс. Найбільший показник перевезених вагонів спостерігається на десятий місяць перевезень і складає 55801 ваг〉міс.

Таким чином, коефіцієнт нерівномірності дорівнює 1.9 , що вказує на наявність впливу сезонного фактора на обсяги перевезень.

Така нерівномірність значно збільшує ризики при оперативному управлінні роботою сортувальних станцій, зокрема в умовах перевезення вагонів з НВ.

Окремо було проведено дослідження функціонування станції Харків-Сортувальний (X-C) i отримано динаміку розподілу кількості вагонів з НВ за добами за жовтень 2020 року (рис. 3). 


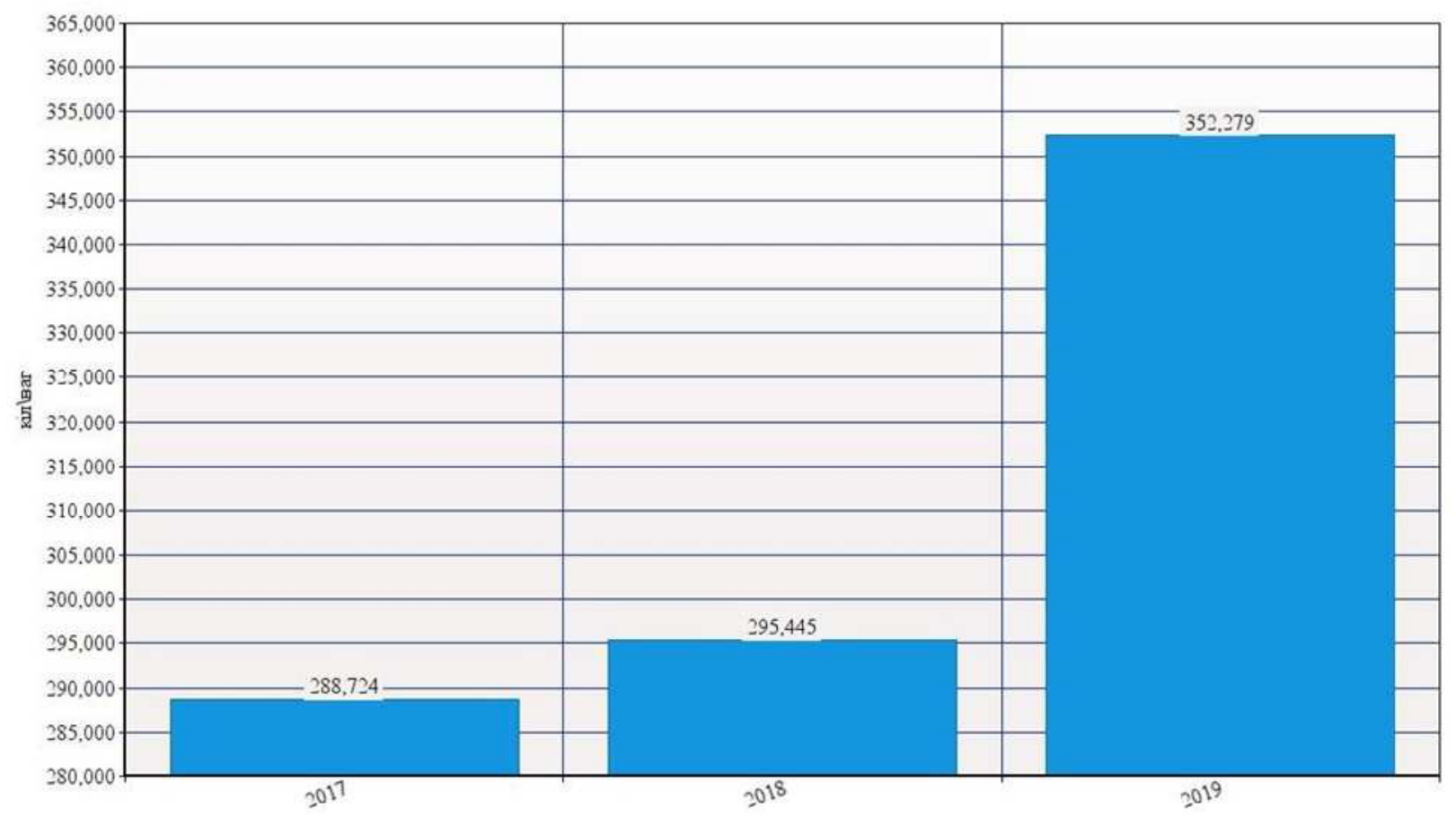

Рис. 1. Динаміка розподілу кількості вагонів з НВ за роками по АТ Укрзалізниця

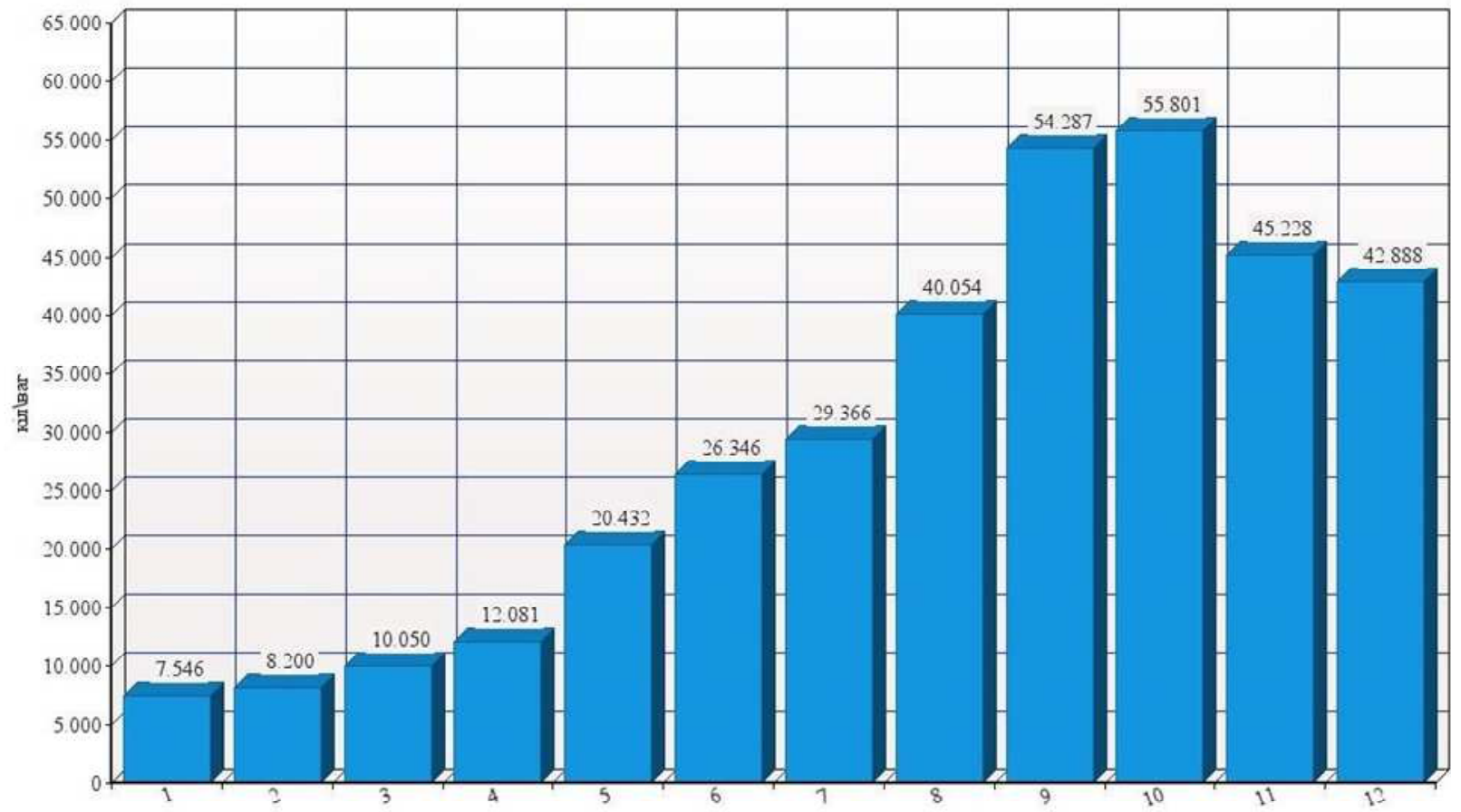

Рис. 2. Динаміка розподілу кількості вагонів з НВ за місяцями протягом 2019 року по АТ Укрзалізниця 


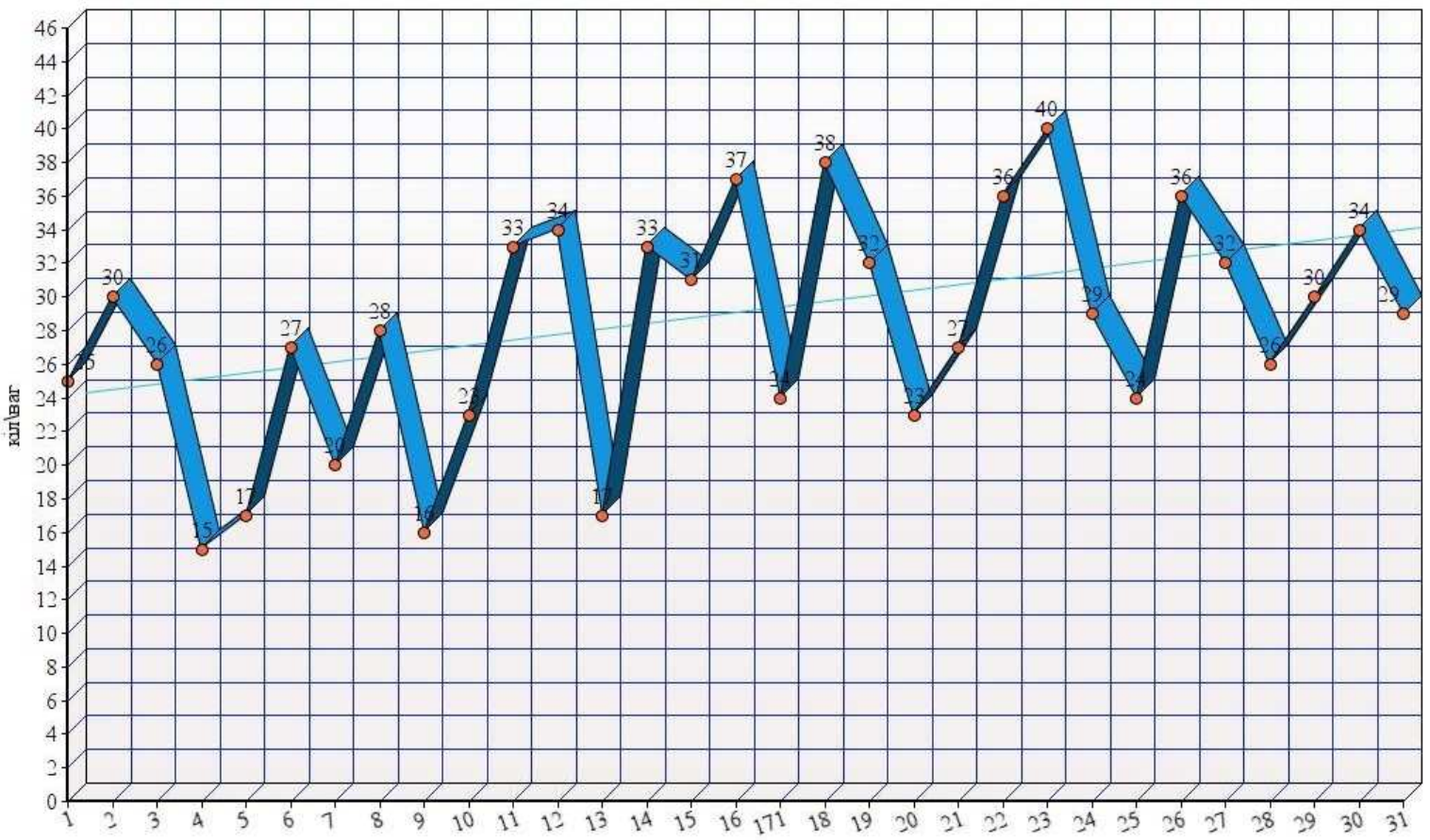

Рис. 3. Динаміка розподілу вагонів з НВ за добами за жовтень 2020 року по станції Харків-Сортувальний

Аналіз отриманої динаміки довів існування значної нерівномірності кількості вагонів $3 \mathrm{HB}$, що підтверджується такими параметрами: в середньому станція Харків-Сортувальний щодоби обробляє $\mathrm{N}$ ваг $=28$, середнє квадратичне відхилення складає $\sigma$ ваг $=13$, тоді як коефіцієнт нерівномірності досягає майже 1.4. Наслідком роботи СС у таких умовах може бути висока імовірність виникнення транспортних подій за участю вагонів з НВ.

Враховуючи вищепроведені дослідження можна констатувати, що сортувальні станції, зокрема станція Харків-Сортувальний, які $є$ головними опорними пунктами при організації вагонопотоків, функціонують в умовах значної нерівномірності, наслідком чого $є$ ускладнення оперативної роботи персоналу. Крім того, в більшості випадків СС розташовуються в межах міста, що підтверджує позачергову важливість автоматизації роботи сортувальних станцій, особливо в умовах обробки вагонів з НВ.

3 метою удосконалення прийняття оперативних управлінських рішень доцільно в рамках автоматизації роботи СC розробити та впровадити систему підтримки прийняття рішень, що базується на технології ризик-менеджменту. Ця технологія передбачає для зменшення імовірності виникнення транспортної події 3 вагонами, завантаженими небезпечними вантажами, розмежувати їх у просторі i часі. У свою чергу ця концепція потребує формалізації роботи СС у вигляді оптимізаційної моделі 3 таким критерієм:

$E(\chi)=\sum_{t=1}^{T} \sum_{i=1}^{W} \sum_{j=1}^{A} \sum_{k=1}^{D}\left(\xi_{i j} H\left(t-t_{j x}^{\Pi}\right) \cdot \zeta_{i k} H\left(t_{k x}^{B}-t\right) \cdot \mathcal{Q}_{i}(t) \cdot L_{i}(t)\right) \rightarrow \min$

де $x$ - змінний вектор, що містить інформацію про послідовність виконання операцій оперативного плану;

$T$ - часовий горизонт планування;

$\mathrm{W}$ - потужність множини вагонів, що розглядаються протягом планового періоду;

А - потужність множини поїздів, що прибувають на станцію протягом планового періоду;
$D$ - потужність множини поїздів, що відправляються зі станції протягом планового періоду;

$\xi_{i j}$ - функція, що набуває значення 1 , якщо $i$-й вагон прибув на станцію у складі $j$-го поїзда, або значення 0 в іншому випадку;

$\zeta_{i k}$ - функція, що набуває значення 1 , якщо $i$-й вагон відправився зі станції у складі $k$-го поїзда, або значення 0 в іншому випадку; 
$t$ - поточне значення часу у хвилинах;

$t_{j x}^{\Pi}$ - час прийняття на станцію $j$-го поїзда;

$t_{k x}^{B}$ - час відправлення зі станції $k$-го поїзда;

$Q_{i}(t)$ - поточне значення функції імовірності виникнення аварії $3 i$-м вагоном, яке може бути отримане за допомогою моделі на основі Баєсової мережі;

$L_{i}(t)$ - поточне значення величини наслідків виникнення аварії з $i$-м вагоном;

$\gamma$ - коефіцієнт нормалізації ймовірностей;

Н - функція Гевісайда, яка визначена таким чином:

$H(z)=\left\{\begin{array}{ll}0 & , z \leq 0 \\ 1 & , z>0\end{array}\right.$.

Запропоновані підходи дають змогу сформувати модель управління ризиками та побудувати на їі основі інтелектуальну систему прийняття рішень оперативного персоналу при управлінні роботою СС в умовах обробки вагонів з НВ.

\section{Висновок}

Вищенаведений аналіз довів, що сортувальні станції, зокрема станція Харків-Сортувальний, працюють в умовах значної нерівномірності при обробці вагонів 3 небезпечними вантажами. Ця тенденція спричиняє додаткові складнощі та ризики в оперативній роботі.

3 метою зменшення цих негативних явищ доцільно сформувати та впроваджувати ризикорієнтовані технології, що дають змогу розмежувати вагони 3 небезпечними вантажами у просторі і часі та стануть основою для подальшої автоматизації роботи СС.

\section{Список використаних джерел}

1. Butko T., Prokhorov V., Chekhunov D. Devising a method for the automated calculation of train formation plan by employing algorithms. EasternEuropean Journal of Enterprise Technologies. 2017. № 85(3Ptl). P. 55-61 (індексується у базі Scopus).

2. Бутько Т. В., Прохоров В. М., Чехунов Д. М. Формалізація технології переробки вагонопотоків iз небезпечними вантажами на сортувальній станції на основі експозиції ризику. Інформаційнокеруючі системи на залізничному транспорті. 2018. № 2. C. 18-22.

3. Бутько Т. В., Прохоров В. М., Чехунов Д. М. Інтелектуальне управління сортувальними станціями при перевезеннях небезпечних вантажів на основі багатоцільової оптимізації. Вісник
Дніпропетровського національного університету залізничного транспорту. 2018. № 5(77). С. 41-52.

4. Regulation concerning the International Carriage of Dangerous Goods by Rail (RID). Intergovernmental Organisation for International Carriage by Rail (2017). Update :11.12.2017. URL: https://otif.fileadmin/new/2-Activities/2D-Dangerousoods/RID_2017_E.pdf (access date 07.11.2018).

5. Аналіз стану безпеки руху поїздів у комерційному господарстві залізниць за 2017 рік. Заходи, спрямовані на покращення стану безпеки руху: Внутрішній документ ПАТ «Укрзалізниця». Сектор аналітики комерційної діяльності та безпеки руху, 2018. 16 c.

6. Anderson R. T., Barkan C.P.L. Railroad accident rates for use in transportation risk analysis. Transportation Reseach Record. 2004. № 1863. Р. 88-98.

7. Формування моделі оцінки ризиків на сортувальній станції при оперуванні вагонами 3 небезпечними вантажами із застосуванням сучасних математичних апаратів / Т. В.Бутько, В. М. Прохоров, Д. М. Чехунов, С. А. Гуровий. Матеріали 80-ї міжнародної науково-технічної конферениії (14-16 травня 2018 р., м. Харків). Частина 1. УкрдУЗТ. 2018. С. 165-166.

8. Чехунов Д. М. Організація вантажопотоків із небезпечними вантажами на основі оптимізації плану формування поїздів. Матеріали 31-ї міжнародної науково-практичної конференциї «Інформаційно-керуючі системи на залізничному транспорті» (24-26 жовтня 2018 р., м. Харків). ІКСТ (додаток). 2018. №4. С. 33.

Бутько Т. В., Костюк А. А. Подходы к формированию риск-ориентированной технологии работы станции Харьков-Сортировочный в условиях обработки вагонов с опасными грузами.

Аннотация. В задачах планирования оперативной работы сортировочной станции (СС), в условиях проведения технологических операций, содержащих вагоны с опасными грузами (ОГ), нужно решать вопрос по совершенствованию работы сортировочных станций, которые обеспечат как сокращение эксплуатационных расходов, так и уменьшение возможных рисков. Результатом решения управленческих задач такой сложности может стать формализация работы сортировочных станций с целью дальнейшей автоматизации процесса принятия решений на основе индивидуально разработанной технологии интеллектуального управления. Для решения такого типа задач была проанализирована технология работы станции Харьков-Сортировочный (Х-С), проведены статистические исследования по количеству вагонов с опасными грузами и времени их пребывания на станции и сформированы подходы к разработке модели оценки риска оперативного 
планирования. Данный анализ представляется перспективным для решения многокритериальных задач, которые возникают в транспортных системах и одновременно являются трудными для формализации. Ключевые слова: вагоны с опасными грузами, сортировочная станция, оперативное управление, автоматизация, оптимизация, технология интеллектуального управления.

Butko T., Kostiuk O. Approaches to the formation of risk-oriented technology of the Kharkiv-Sortirovochny station in the conditions of processing of cars with dangerous goods.

Abstract. In the tasks of planning the operational work of the sorting station (SS), in terms of technological operations containing wagons with dangerous goods (DG), it is necessary to address issues of improving the operation of sorting stations, which will reduce both operating costs and reduce possible risks. The result of solving management problems of such complexity can be the formalization of sorting stations in order to further automate the decision-making process based on individually developed technology of intelligent control. To solve this type of problem, the technology of KharkivSortirovochny (K-S) station was analyzed and statistical studies on the number of wagons with dangerous goods and their stay at the station were conducted and approaches to developing a risk assessment model for operational planning were formed. This analysis is promising for solving multicriteria problems that arise in transport systems and which are also difficult to formalize. Key words: wagons with dangerous goods, sorting station, operational management, automation, optimization, intelligent control technology.

Надійшла 15.01.2021 p.
Butko Tetiana Vasylivna, Dr.Sc., professor, chief of department, department of Menagement of operational work, Ukrainian State University of Railway Transport, Kharkiv, Ukraine.E-mail: butko@kart.edu.ua

http://orcid.org/0000-0003-1082-599X

Kostiuk Oleksandr Anatoliyovych, master, department of Menagement of operational work, Ukrainian State University of Railway Transport, Kharkiv, Ukraine.

E-mail:111111155555555yulia@gmail.com

Бутько Тетяна Василівна, д.т.н., професор, завідувач кафедри «Управління експлуатаційною роботою», Украӥнський державний університет залізничного mpaнcnopmy.E-mail: butko@kart.edu.ua http://orcid.org/0000-0003-1082-599X

Костюк Олександр Анатолійович, магістрант, кафедра «Управління експлуатаційною роботою», Украӥнський державний університет залізничного транспорту.

E-mail: 111111155555555yulia@gmail.com 